\title{
Managing challenging behaviour in children with possible learning disability
}

\author{
Michael Absoud consultant in paediatric neurodisability and senior clinical lecturer ${ }^{1}$, Holly Wake \\ research assistant ${ }^{2}$, Miriam Ziriat research assistant ${ }^{2}$, Angela Hassiotis professor of psychiatry of \\ intellectual disability ${ }^{2}$
}

${ }^{1}$ Newcomen Centre at St Thomas', St Thomas' Hospital, London, UK; ${ }^{2}$ Division of Psychiatry, University College London, London, UK

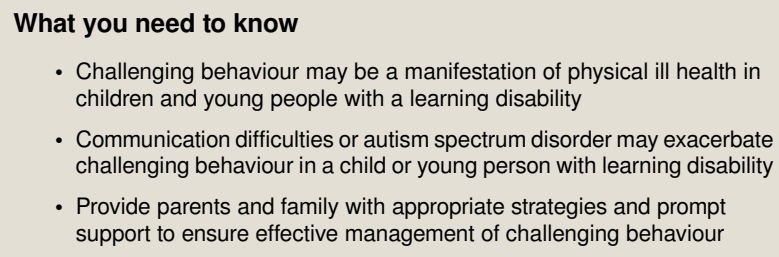

A mother visits her general practitioner with her 3 year old daughter. She is concerned that the child is having regular "melt downs" and has become defiant when, for example, getting dressed or putting on her shoes. Her daughter is physically aggressive towards her and other family members. This happens often and sometimes lasts for up to an hour. The family has tried reward charts, time outs, and positive reinforcement.

Challenging behaviour is commonly defined as behaviour that is of an intensity, frequency, or duration that threatens the physical safety of the person or others or restricts access to community facilities. ${ }^{12}$ Challenging behaviour can first occur in childhood and can be difficult for parents, carers, and family members to understand and manage. Parents and carers may present to healthcare services, including their GP, with concerns about their children's behaviour.

In some cases, challenging behaviour may be a sign of a known or an undiagnosed learning disability. This article gives particular advice about how to identify and manage children where a learning disability might be a contributing factor.

\section{What you should cover}

Often, behaviours perceived as challenging serve a purpose for the child or young person, such as producing sensory stimulation, attracting attention, and avoiding demands. ${ }^{3}$ Some behaviours may be a form of communication which needs to be understood.
Examples of challenging behaviours, sometimes reported by parents as "melt downs" or "defiance," are

- Physical aggression (biting, scratching, hitting)

- Self injury (head banging, biting hands)

- Stereotyped (repetitive movements, rocking, repetitive speech)

- Non-person directed (damage to property, hyperactivity, sleep and eating problems).

Explore how the behaviours have started and any child or family factors that may have contributed to the presentation. Ask the parents how they cope and what they understand about their child's behaviour. Find out about the child's medical history, including any serious physical illness or abuse.

More specifically:

- Ask what the behaviour is; where and when it occurs; and how often and for how long. What are the immediate triggers, how risky is it, and how much distress does it cause?

- Ask about physical and mental health comorbidities and whether the child has or is being investigated for learning disability, developmental delay, or autism spectrum disorder

- Explore the mental health and social care needs of the parents and siblings of a child who displays challenging behaviour

- Check whether the parents have discussed the issues with the health visitor (for children under 5) or whether they have been referred to the child and adolescent mental health services.

Typical behaviour and development in preschool children has a wide range, and primary care practitioners should consider this to avoid over-referral and pathologising behaviours. ${ }^{4}$ The early years foundation stage ${ }^{5}$ provides a useful list of learning goals for the preschool child (3-5 years), which may be useful in distinguishing typical and challenging behaviour in this age group (box 1). 


\section{Box 1: Early learning goals in preschool children}

Communication and language

o Listening and attention: children listen attentively in a range of situations. They listen to stories, anticipating key events, and respond to what they hear with relevant comments

o Understanding: children follow instructions involving several ideas or actions. They answer "how" and "why" questions about their experiences o Speaking: children express themselves effectively, showing awareness of listeners' needs. They develop narratives and explanations by connecting ideas or events

\section{Physical development}

o Moving and handling: children show good coordination. They move confidently in a range of ways, safely negotiating space. They handle equipment and tools effectively

o Health and self care: children know ways to keep healthy and safe. They manage their own basic hygiene and personal needs, including dressing and toileting

\section{Personal, social, and emotional development}

o Self confidence and self awareness: children are confident to try new activities and speak in a familiar group about their ideas. They say when they do or don't need help

o Managing feelings and behaviour: children talk about how they and others show feelings, talk about their own and others' behaviour and its consequences, and know that some behaviour is unacceptable. They work as part of a group or class, and understand and follow the rules. They adjust their behaviour to different situations, and easily adapt to changes of routine

o Making relationships: children play cooperatively, taking turns with others. They take account of one another's ideas about how to organise their activity. They show sensitivity to others' needs and feelings, and form positive relationships with others

\section{What to include in an initial assessment Is there an underlying learning disability?}

Challenging behaviour can occur with or without a learning disability or other neurodevelopmental diagnosis. Additionally, children may present with social communication difficulties that are indicative of a diagnosis of autism, but not have a learning disability or challenging behaviour. ${ }^{6}$

Learning disability (also known as "intellectual developmental disorder" or "intellectual disability") is a lifelong condition with onset during the early years, characterised by deficits in both intellectual and adaptive functioning. ${ }^{7}$ Approximately 355000 children and young people in the UK have a learning disability, most of whom will not present with challenging behaviour. ${ }^{8}$ However, approximately 40000 display challenging behaviour and other neurodevelopmental, physical, and mental health comorbidities (such as genetic conditions, epilepsy, autism, attention deficit/hyperactivity disorder (AD/HD), conduct disorder anxiety, or sensory difficulties).

\section{Assessment of a child with possible learning disability and challenging behaviour}

The clinician should ask parents for their view of the child's developmental age and functioning, ${ }^{9}$ as parents are often accurate at estimating level of functioning, and this could also give an indication about expectation and whether there is a likely gap between intellectual functioning and adaptive functioning (abilities in carrying out everyday life skills). Carry out a thorough assessment of the child's physical health status. Where a child presents with developmental delay suggestive of a learning disability, there may be additional problems in the child expressing discomfort or pain. Carrying out basic procedures such as an ear, nose, and throat examination and abdominal inspection and palpation are important in potentially identifying physical health morbidity. ${ }^{10}$

Be mindful of diagnostic overshadowing, ${ }^{11}$ a common situation where clinicians attribute symptoms or behaviours to the learning disability instead of comorbid psychopathology. Overshadowing may also result from investigating medical conditions rather than assessing learning or behaviour (for example, focusing on treating epilepsy without thinking of the "whole child"). Relevant questions that may reveal other reasons behind the presenting behaviour could be: How would you pick your child out from a group of children with a similar developmental level? Does his/her behaviour vary with the medical condition or medication changes? What do you think your child's behaviour is communicating (pain, sensory sensitivity, frustration)?

Once physical ill health has been considered, look for evidence of comorbidities such as $\mathrm{AD} / \mathrm{HD}$, autism spectrum disorder, emotional problems (also called internalising disorders), or peer and conduct problems (also called externalising disorders). ${ }^{12}$ Internalising problems include reporting pain, being easily scared, being often unhappy or nervous, being victimised or bullied, and tending to play alone. Externalising problems include hyperactivity, temper tantrums, disobedience, and fights with other children. The full range of presentations is associated with the level of functioning and communication ability of the child. ${ }^{13-16}$

Box 2 lists genetic disorders that are associated with medical and emotional disorders in people with learning disabilities.

\section{Box 2: Genetic syndromes and comorbidities}

Painful gastrointestinal reflux may result in self injury ${ }^{17}$ in individuals with Cornelia de Lange syndrome

o Temper outbursts may relate to access/timing of food in Prader-Willi syndrome $^{18}$

o Hamartomas may cause kidney pain

o Headaches can be seen in patients with tuberous sclerosis complex ${ }^{19}$

o Autism and psychosis ${ }^{20}$ are strongly associated with $22 q 11.2$ deletion syndrome

o Hyperactivity, stereotyped movements, and unusual speech ${ }^{21}$ are associated with Fragile $\mathrm{X}$ syndrome, which is the most common inherited cause of learning disability

\section{Risk assessment}

Children and young people with challenging behaviour and particularly those with a learning disability are at a substantially higher risk than other children for all forms of abuse, neglect, and social disadvantage. Consider whether there are any safeguarding concerns, and check whether the child or anyone else is at risk. Conduct a brief risk assessment, paying particular attention to the areas outlined in box 3 . 


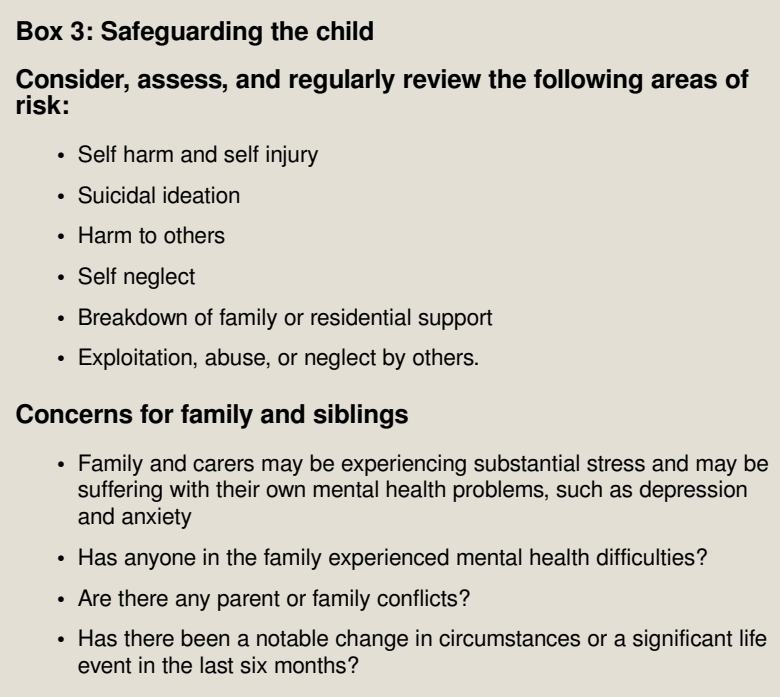

\section{What is the initial management?}

Provide reassurance to the parents that their concerns are taken seriously and that they are not being blamed. Initial management may include advice on simple behaviour techniques to encourage appropriate behaviour (box 4) and referral to parenting courses available locally.

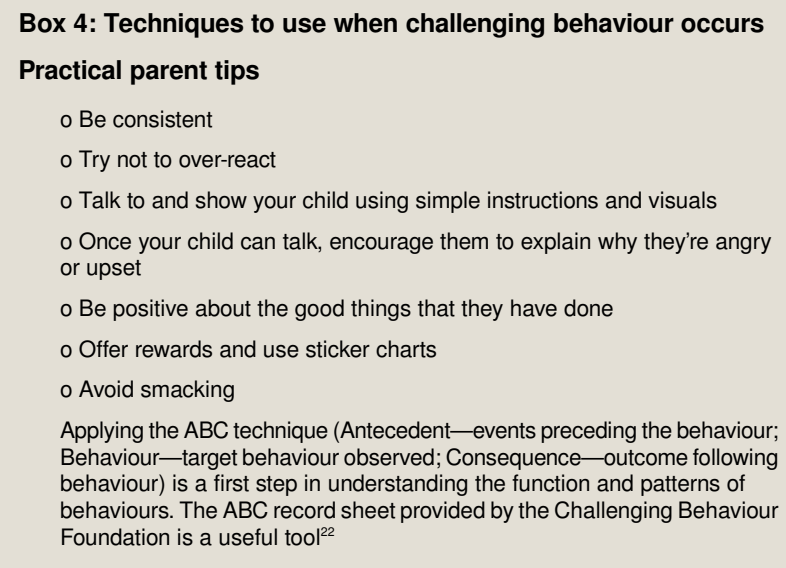

\section{When you should refer}

Refer for specialist assessment when

- The behaviour occurs regularly

- The behaviour is persisting or seems to be getting worse

- The child or young person is self injuring (head banging, biting hands)

- The child or young person is physically aggressive to others (biting, scratching, hitting)

- The severity and frequency of the behaviours are having a detrimental effect on the child or young person, the parent or carer, or the wider family.

Although there is no specific time criterion for a referral, the severity or urgency of the presenting problem may require a prompt response, especially when simple behaviour techniques have not led to improvement in behaviour. We suggest the following broad principles guiding referrals:

- Child and adolescent mental health services—need for family systemic work and concerns with possible mental health conditions such as depression, anxiety disorders, self harm, abuse, violence or anger, obsessive convulsive disorders, $\mathrm{AD} / \mathrm{HD}$. Child is usually over 5

\section{- Community paediatrics — concerns with possible}

neurodevelopmental disorders such as autism spectrum disorder; $\mathrm{AD} / \mathrm{HD}$; tics; learning disability or delay in development; motor disorders

- Social services-if there are concerns that the child has suffered substantial harm; is likely to suffer substantial harm; has a disability, developmental and welfare needs which are likely only to be met through provision of family support services; is a Child in Need whose development would be likely to be impaired without provision of services.

In the UK, children under 5 are usually referred to child development teams. Such teams provide diagnostic and therapeutic services and are staffed by a range of professionals including speech and language therapy, occupational therapy, psychological or psychiatric input, psychotherapy, nursing, and social workers.

Each child development team accepts referrals from health, social care, or education professionals. Children over 5 can be referred to the child and adolescent mental health services for further assessment and management of a possible mental disorder such as depression or anxiety. Community learning disability services accept adults aged 18 and over. Usually, children with a learning disability in education will be known to transition social workers, who will facilitate the referral to the adult services. Assessments of those young people commences around age 14 and they and their families should be closely involved to set goals for outcomes they want to achieve in adulthood.

\section{What treatment options are available?}

A suggested clinical pathway for children with possible learning disability and challenging behaviour is presented in fig 1 .

Dependent on the complexity of the case and whether a diagnosis of learning disability is confirmed, a child may be under paediatric or psychiatric review and care coordination of the overall support package. Often, the family may receive respite and other social care provided by third sector agencies. Most children will be in education and therefore will be supported and reviewed at nursery or at school. Schools for children and young people with learning disability usually will have input from speech and language therapists, psychologists, nurses, and psychiatrists, who will review the children where teachers may have expressed concerns.

Local authorities in England have services for children and young people aged 0-25 with learning disabilities and their families, often called "the local offer." Signposting the family to local resources can be helpful, especially at a time when they may be dealing with a new diagnosis and its long term impact on family life. Families with multiple difficulties including adverse social circumstances may already have an allocated social or family support worker. In those instances of families with complex needs, it is necessary to liaise with multiple agencies and professionals-for example, where there are safeguarding issues, parental mental ill health, or other issues.

In the UK, the Care Act $2014^{23}$ is the framework within which a family's needs are assessed and eligibility of additional state funded support is decided.

Below we briefly describe common interventions that may be available in different areas. 


\section{Psychosocial}

Behavioural interventions, such as applied behaviour analysis, are widely used to enhance prosocial behaviour in children and young people with learning disability and increasingly to reduce challenging behaviour. Positive behaviour support, an evidence based intervention, is now delivered by many psychologists for children and adults with learning disability who display challenging behaviour. ${ }^{24}$

Parent training, usually provided in groups of up to 12 , is an effective way of teaching parents skills in the effective management of challenging behaviour in their child. ${ }^{25}$ Those programmes are adapted from parent training groups of children without learning disability who may have a conduct disorder. ${ }^{26}$ One such programme, which is being tested currently, is Stepping Stones Triple P. ${ }^{2728}$ Some services may also offer individual therapy to the child or young person with mild learning disability as well as family therapy aimed at building resilience and coping strategies. Therapists should make reasonable adjustments and adaptations to account for any cognitive deficits, communication difficulties, and sensory impairments.

Early Bird and Early Bird Plus programmes developed by the National Autistic Society are designed for children with autism spectrum disorders, but they may also be useful for some parents of children with learning disability and challenging behaviour.

\section{Drug treatment}

For a proportion of children with severe difficulties, psychotropic medication (such as stimulants and antipsychotics) may be needed. These should be prescribed only in conjunction with psychosocial interventions or where challenging behaviour leads to a crisis and behavioural interventions have proved ineffective. ${ }^{1}$ Specialist paediatricians or child psychiatrists may consider prescribing appropriate medication to treat specific disorders such as AD/HD.

Antipsychotic medications such as aripiprazole and risperidone have been shown to be effective in reducing challenging behaviours among children and young people with learning disability and autism spectrum disorders in the short term. Ongoing monitoring for weight gain and other side effects is required. ${ }^{29}$ Prescribers must follow guidelines in initiating and monitoring psychotropic medication. They must consult with the parents and the child, where possible, about ongoing treatment and the benefits and potential harms from it. Any decisions should be clearly documented and withdrawal of medication should be discussed at the earliest opportunity.

\footnotetext{
Education into practice

- What comorbidities might you consider when assessing a child or young person with challenging behaviour?

- How do you assess risk and safeguarding when reviewing a child with challenging behaviour and/or a learning disability?

- What services are available locally where you could refer a child with challenging behaviour?
}

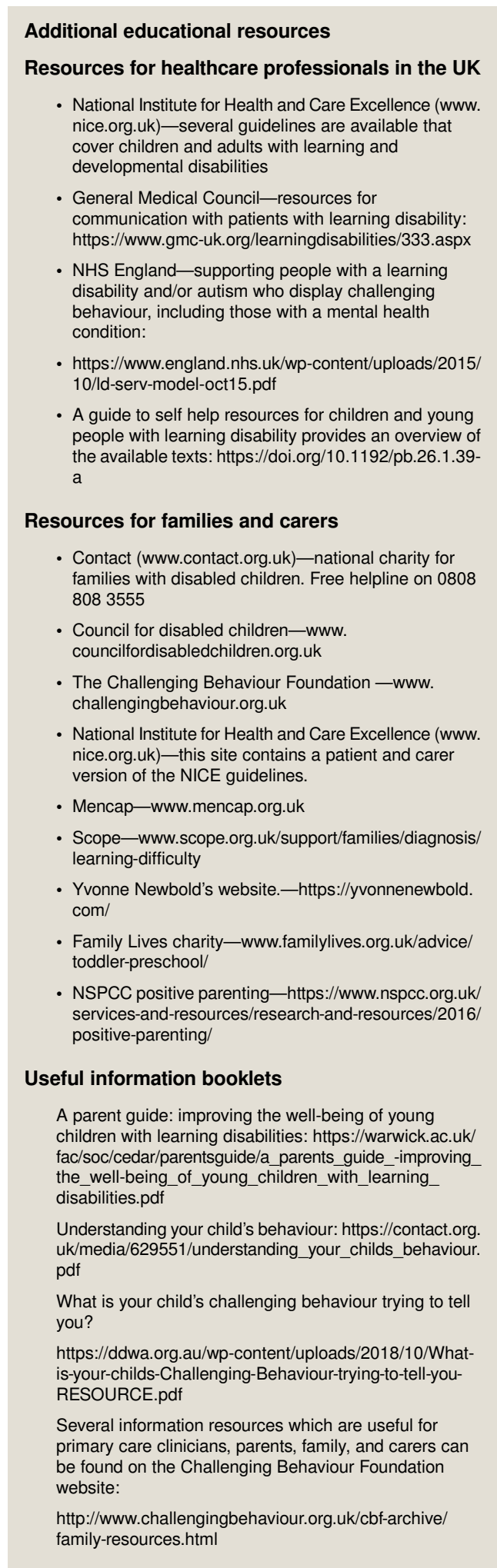

\section{Search strategy for article}

A PubMed search using the terms "intellectual developmental disorder," "intellectual disability," "learning disability," "challenging behaviour," "child" and "adolescent" was performed. We examined Cochrane and other relevant systematic reviews, meta-analyses and treatment trials. We supplemented this information with additional searches-eg, reference lists, Google scholar, and our knowledge of the subject area. 


\section{How patients were involved in the creation of this article}

The parent advisory group of a clinical trial currently under way (https://www. ucl.ac.uk/psychiatry/research/epidemiology/pis/hassiotis-research-portfolio/ challenging-behaviour-early-intervention), who are experts by experience as their children have a learning disability and display challenging behaviour, were involved in the development of the article. They provided the case study and read versions of the manuscript before submission. They commented on the referral pathway and talked about their experiences of services and how they understand the behaviour in the context of their child's specific needs and strengths.

Competing interests The $B M J$ has judged that there are no disqualifying financial ties to commercial companies. The authors declare the following other interests: none.

Further details of The BMJ policy on financial interests are here: https://www.bmj. com/about-bmj/resources-authors/forms-policies-and-checklists/declarationcompeting-interests

Contributorship statement and guarantor: All authors contributed to the planning, conduct, and reporting of the work described in the article. $\mathrm{AH}$ had the idea for the article, $\mathrm{HW}$ performed the literature search, $\mathrm{HW}$ and $\mathrm{MZ}$ wrote the first draft. $\mathrm{AH}$ and MA are responsible for the overall content as guarantors.

Contributors: EPICC-ID trial management team (Jacqueline Barnes, Marinos Kyriakopoulos, Kate Oulton, Eleni Paliokosta, Aditya Sharma, Vicky Slonims, Una Summerson, Megan Thomas, Alastair Sutcliffe).

Parent advisory group: Rebecca Scurr and Nikki Kimber.

Provenance and peer review: commissioned, based on an idea from the author; externally peer reviewed.

1 National Institute for Health and Care Excellence. Challenging behaviour and learning disabilities: prevention and interventions for people with learning disabilities whose behaviour challenges. London, 2015. https://www.nice.org.uk/guidance/ng11/resources/ challenging-behaviour-and-learning-disabilities-prevention-and-interventions-for-peoplewith-learning-disabilities-whose-behaviour-challenges-1837266392005

2 Emerson E, Bromley J. The form and function of challenging behaviours. J Intellect Disabil Res 1995;39:388-98. 10.1111/j.1365-2788.1995.tb00543.x 8555715

3 Green J, Absoud M, Grahame V, etal . Pathological Demand Avoidance: symptoms but not a syndrome. Lancet Child Adolesc Health 2018;2:455-64. 10.1016/S2352-4642(18)30044-0 30169286

4 Bellman M, Byrne O, Sege R. Developmental assessment of children. BMJ 2013;346:e8687. 10.1136/bmj.e8687 23321410

5 Department of Education. Statutory framework for the early years foundation stage. Ref: DFE-00169-2017. 2017. https://www.gov.uk/government/uploads/system/uploads/ attachment_data/file/596629/EYFS STATUTORY FRAMEWORK_2017.pdt.

6 Lord C, Elsabbagh M, Baird G, Veenstra-Vanderweele J. Autism spectrum disorder Lancet 2018;392:508-20. 10.1016/S0140-6736(18)31129-2 30078460

7 Diagnostic and statistical manual of mental disorders. Neurodevelopmental disorders. Am Psych Assoc, 2013.

8 Emerson E, Hastings R, McGill P, Pinney A, Shurlock J. Estimating the number of children in England with learning disabilities and whose behaviours challenge. Challenging Behaviour Foundation. 2014. http://www.challengingbehaviour.org.uk/learning-disabilityfiles/Estimating-the-Number-of-Children-with-LD-and-CB-in-England.pdf.
9 Chandler S, Howlin P, Simonoff E, Kennedy J, Baird G. Comparison of parental estimate of developmental age with measured IQ in children with neurodevelopmental disorders. Child Care Health Dev 2016;42:486-93. 10.1111/cch.12346 27126521

10 McClintock K, Hall S, Oliver C. Risk markers associated with challenging behaviours in people with intellectual disabilities: a meta-analytic study. $J$ Intellect Disabil Res 2003;47:405-16. 10.1046/j.1365-2788.2003.00517.x 12919191

11 Ali A, Hassiotis A. Illness in people with intellectual disabilities. BMJ 2008:336:0-D.

12 Davies $\mathrm{L}$, Oliver $\mathrm{C}$. The age related prevalence of aggression and self-injury in persons with an intellectual disability: a review. Res Dev Disabil 2013;34:764-75. 10.1016/j.ridd.2012.10.004 23220053

13 Moeschler JB, Shevell MCommittee on Genetics. Comprehensive evaluation of the child with intellectual disability or global developmental delays. Pediatrics 2014;134:e903-18. 10.1542/peds.2014-1839 25157020

14 Families Special Interest Research Group of IASSIDD. Families supporting a child with intellectual or developmental disabilities: the current state of knowledge. J Appl Res Intellect Disabil 2014;27:420-30. 10.1111/jar.12078 25254268

15 Baker BL, McIntyre LL, Blacher J, Crnic K, Edelbrock C, Low C. Pre-school children with and without developmental delay: behaviour problems and parenting stress over time. $J$ Intellect Disabil Res 2003:47:217-30. 10.1046/j.1365-2788.2003.00484.x 12787154

16 Emerson $E$. Mothers of children and adolescents with intellectual disability: social and economic situation, mental health status, and the self-assessed social and psychological impact of the child's difficulties. J Intellect Disabil Res 2003;47:385-99. 10.1046/j.1365-2788.2003.00498.x 12787168

17 Luzzani S, Macchini F, Valadè A, Milani D, Selicorni A. Gastroesophageal reflux and Cornelia de Lange syndrome: typical and atypical symptoms. Am J Med Genet $A$ 2003;119A:283-7. 10.1002/ajmg.a.20191 12784293

18 Butler JV, Whittington JE, Holland AJ, Boer H, Clarke D, Webb T. Prevalence of, and risk factors for, physical ill-health in people with Prader-Willi syndrome: a population-based study. Dev Med Child Neurol 2002;44:248-55. 10.1017/S001216220100202X 11995893

19 Orlova KA, Crino PB. The tuberous sclerosis complex. Ann N Y Acad Sci 2010;1184:87-105. 10.1111/j.1749-6632.2009.05117.x 20146692

20 Schneider M, Debbané M, Bassett AS, etal International Consortium on Brain and Behavior in 22q11.2 Deletion Syndrome. Psychiatric disorders from childhood to adulthood in 22q11.2 deletion syndrome: results from the International Consortium on Brain and Behavior in 22q11.2 Deletion Syndrome. Am J Psychiatry 2014;171:627-39 10.1176/appi.ajp.2013.13070864 24577245

21 Baumgardner TL, Reiss AL, Freund LS, Abrams MT. Specification of the neurobehavioral phenotype in males with fragile X syndrome. Pediatrics 1995;95:744-52.7724315

22 Challenging Behaviour Foundation. http://www.challengingbehaviour.org.uk/learning disability-files/02-Finding-the-Causes-of-Challenging-Behaviour-Part-2-web.pdf.

23 Care Act. 2014. https://www.scie.org.uk/care-act-2014/assessment-and-eligibility/

24 lemmi V, Knapp M, Brown FJ. Positive behavioural support in schools for children and adolescents with intellectual disabilities whose behaviour challenges: An exploration of the economic case. J Intellect Disabil 2016;20:281-95.

$10.1177 / 174462951663240226912505$

25 Skotarczak L, Lee GK. Effects of parent management training programs on disruptive behavior for children with a developmental disability: a meta-analysis. Res Dev Disabil 2015;38:272-87. 10.1016/j.ridd.2014.12.004 25577178

26 Webster RI, Majnemer A, Platt RW, Shevell MI. Child health and parental stress in school-age children with a preschool diagnosis of developmental delay. J Child Neurol 2008:23:32-8. 10.1177/0883073807307977 18184941

27 Tellegen CL, Sanders MR. Stepping Stones Triple P-Positive Parenting Program for children with disability: a systematic review and meta-analysis. Res Dev Disabil 2013;34:1556-71. 10.1016/j.ridd.2013.01.022 23475006

28 NHS Health Research Authority. Clinical and cost effectiveness of a parent mediated intervention to reduce challenging behaviour in pre-schoolers with moderate to severe learning disability: a randomised controlled trial. https://www.hra.nhs.uk/planning-andimproving-research/application-summaries/research-summaries/epicc-id-randomisedcontrolled-trial

29 McQuire C, Hassiotis A, Harrison B, Pilling S. Pharmacological interventions for challenging behaviour in children with intellectual disabilities: a systematic review and meta-analysis. BMC Psychiatry 2015;15:303. 10.1186/s12888-015-0688-2 26611280

Published by the BMJ Publishing Group Limited. For permission to use (where not already granted under a licence) please go to http://group.bmj.com/group/rights-licensing/ permissions 


\section{Figure}

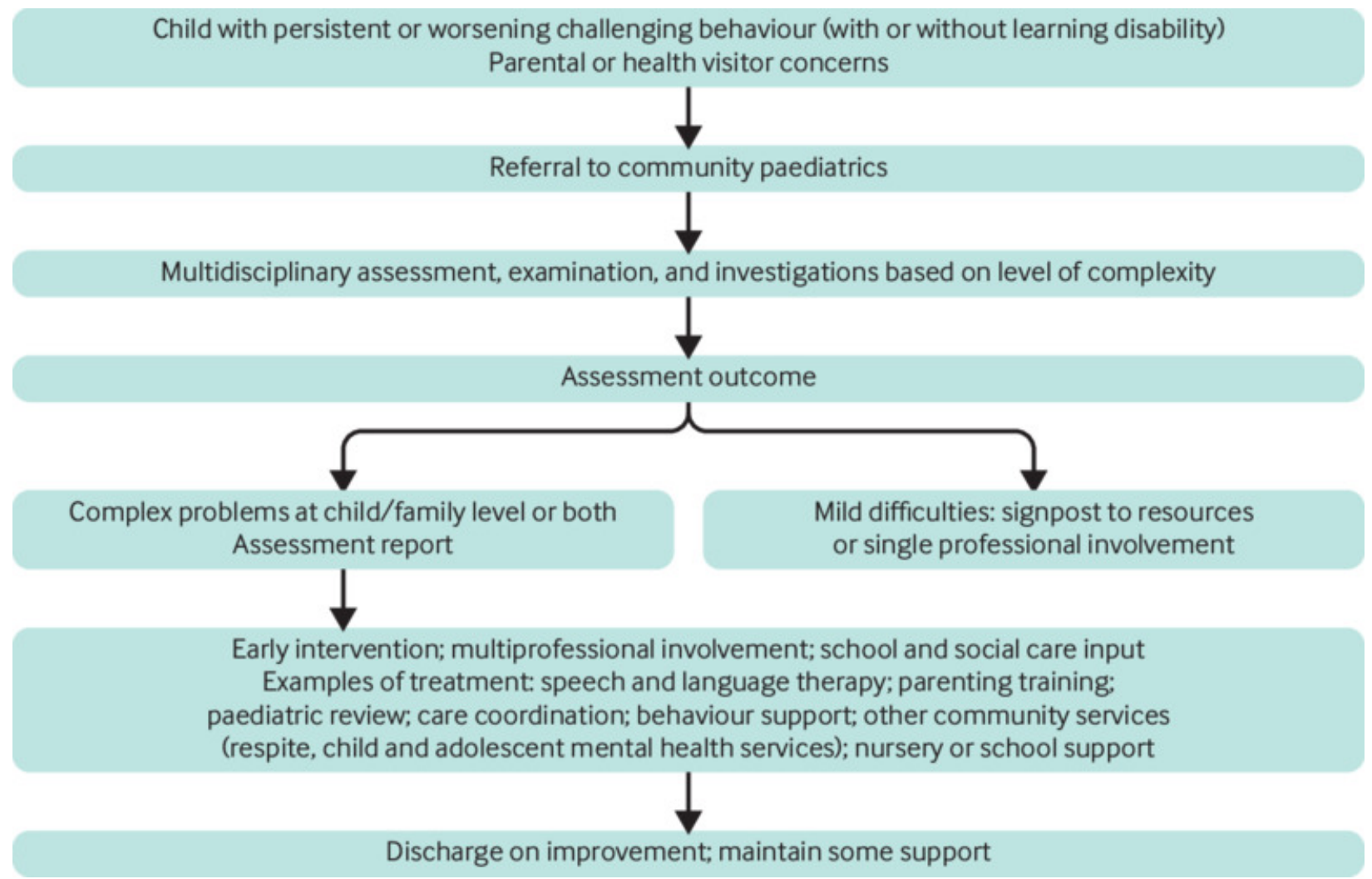

Fig 1 Clinical pathway 